\title{
Fabrication and Characterization of Thin Film Solar Cell Made from CuIn $0.75 \mathrm{Ga}_{0.25} \mathrm{~S}_{2}$ Wurtzite Nanoparticles
}

\author{
Fengyan Zhang, ${ }^{1}$ Chivin Sun, ${ }^{2}$ Cyril Bajracharya, ${ }^{2}$ Rene G. Rodriguez, ${ }^{2}$ and Joshua J. Pak ${ }^{2}$ \\ ${ }^{1}$ Institute for Solar Energy, Xiamen University, Xiamen, Fujian, China \\ ${ }^{2}$ Department of Chemistry, Idaho State University, Pocatello, ID 83209, USA \\ Correspondence should be addressed to Fengyan Zhang; fengyanzhang1@gmail.com and Joshua J. Pak; pakjosh@isu.edu
}

Received 20 February 2013; Revised 17 April 2013; Accepted 7 May 2013

Academic Editor: Weidong Zhou

Copyright (C) 2013 Fengyan Zhang et al. This is an open access article distributed under the Creative Commons Attribution License, which permits unrestricted use, distribution, and reproduction in any medium, provided the original work is properly cited.

$\mathrm{CuIn}_{0.75} \mathrm{Ga}_{0.25} \mathrm{~S}_{2}$ (CIGS) thin film solar cells have been successfully fabricated using CIGS Wurtzite phase nanoparticles for the first time. The structure of the cell is Glass/Mo/CIGS/CdS/ZnO/ZnO:Al/Ag. The light absorption layer is made from CIGS Wurtzite phase nanoparticles that are formed from single-source precursors through a microwave irradiation. The Wurtzite phase nanoparticles were converted to Chalcopyrite phase film through a single-step annealing process in the presence of argon and sulfur at $450^{\circ} \mathrm{C}$. The solar cell made from Wurtzite phase nanoparticles showed $1.6 \%$ efficiency and 0.42 fill factor.

\section{Introduction}

Current CIGS thin film solar cells using evaporation or sputtering processes are expensive, and the composition uniformity is difficult to control on a large scale. Recent studies show that through spraying or printing, the light absorption layer can be made from a nanoparticle ink, which shows promise to reduce the fabrication cost of the solar cell significantly [1-5]. But, the process to convert nanoparticle layers into a dense film with large grain-sizes and a pin hole/crack-free surface is difficult to achieve. Large particle sizes with more labile passivation ligands are preferred in order to lower the thermal budget and reduce the cost of the sintering process. More labile ligands require a lower temperature for their removal, and larger particles have less passivation layer to remove, relatively speaking, since their surface area to volume ratio is lower. The solution method does not lend itself well to the growth of larger CIGS nanoparticles in the Chalcopyrite phase. In our case, we chose to use large-sized CIGS particles in a different metastable phase, Wurtzite particles, and then convert them into a Chalcopyrite phase CIGS thin film at higher temperature.
The CIGS Wurtzite phase has been prepared by several research groups recently [6-15], and it has the same composition as the Chalcopyrite phase. Wurtzite phase is a cation disordered polymorph of Chalcopyrite with copper and indium cations randomly sharing common lattice sites. It belongs to space group P63mc with $a=0.390652 \mathrm{~nm}$ and $c=6.42896 \mathrm{~nm}$. The hexagonal plate-shaped nanocrystals offer potential to be packed differently compared to spherical Chalcopyrite nanoparticles and ultimately produce a large grain size and better connectivity in the resulting film when annealed. Since the CIGS Wurtzite phase is a metastable phase, it can be effectively converted to a Chalcopyrite phase via simple thermal treatment at high temperature [6]. The growth process of the Wurtzite phase nanoparticles is also controllable, and it has been demonstrated that certain reaction conditions can be used to produce large-sized hexagonal plate particles with a lower surface area to volume ratio than smaller Chalcopyrite particles. Steinhagen et al. recently reported the use of $\mathrm{CuInSe}_{2}$ Wurtzite nanowires in the fabrication of solar cells with $0.1 \%$ efficiency [15]. To the best of our knowledge, Wurtzite structured CIGS nanoparticles 
have not been fabricated into a solar cell. In this paper, we describe the procedures of fabricating a CIGS thin film solar cell from large metastable Wurtzite phase nanoparticles.

\section{Experimental}

2.1. Device Construction. The device structure used in these studies is one that is commonly used for CIGS thin film cell construction, Glass/Mo/CIGS/CdS/ZnO/ZnO:Al/Ag [16]. The Mo layer was deposited by DC sputtering using a Denton Desktop Pro. The current used was $300 \mathrm{~mA}$ and the pressure was held at $0.67 \mathrm{~Pa}$. The thickness of Mo layer was $0.5 \mu \mathrm{m}$ with resistivity of $5 \times 10^{-5} \mathrm{ohm}-\mathrm{cm}$. Thin film of Wurtzite CIGS absorber layer was deposited using an ink containing $20 \mathrm{wt} \%$ nanoparticles in toluene on top of the Mo.

The CIGS nanoparticles were synthesized by decomposing the appropriate single source precursors (SSPs), $\left(\mathrm{Ph}_{3} \mathrm{P}\right)_{2} \mathrm{Cu}\left(\mu-\mathrm{SC}_{2} \mathrm{H}_{5}\right)_{2} \mathrm{In}\left(\mathrm{SC}_{2} \mathrm{H}_{5}\right)_{2} \quad$ (1) and $\left(\mathrm{Ph}_{3} \mathrm{P}\right)_{2} \mathrm{Cu}(\mu-$ $\left.\mathrm{SC}_{2} \mathrm{H}_{5}\right)_{2} \mathrm{Ga}\left(\mathrm{SC}_{2} \mathrm{H}_{5}\right)_{2}(2)$, as described in the literature [1721]. Using this established procedure, CIGS nanoparticles containing $75 \%$ In and $25 \% \mathrm{Ga}$, in primarily Wurtzite phase, were obtained. In Figure 1, the TEM micrograph of CIGS nanoparticles clearly shows hexagonal plate features of Wurtzite phase mixed with some very smaller Chalcopyrite nanoparticles. The SAED data is consistent with predominant Wurtzite phase mixed in with Chalcopyrite (Figure 1).

The Wurtzite CIGS nanoparticles were made into an ink containing $20 \mathrm{wt} \%$ nanoparticles in toluene. The doctor blade technique was used to apply the film onto the Mo surface; then a pressure of $68.9 \mathrm{MPa}$ was used to increase the density of the film. Annealing in a sulfur and argon atmosphere was then performed at $450^{\circ} \mathrm{C}$. This temperature was chosen because thermal gravimetric analysis/mass spectrometry analysis of Wurtzite nanoparticles indicated that alkyl sulfide passivating groups leave the CIGS nanoparticle at temperatures between 250 and $350^{\circ} \mathrm{C}$ [18]. In addition, the phase conversion from Wurtzite to Chalcopyrite, recrystallization and grain growth of the CIGS thin films normally occur between $450-600^{\circ} \mathrm{C}$ [6]. In order to minimize the defects in the CIGS film and to achieve the required thickness, three applications of the CIGS layer were performed followed by annealing at $450^{\circ} \mathrm{C}$. The thickness of CIGS layer used in the solar cells was $5 \mu \mathrm{m}$ based on SEM measurements. After forming the light absorbing layer, the rest of the $\mathrm{CdS} / \mathrm{ZnO} /$ $\mathrm{ZnO}$ :Al layers were fabricated.

The CdS buffer layer was deposited on the CIGS using the chemical bath deposition method from aqueous solutions of $\mathrm{CdCl}_{2} \cdot 2 \mathrm{H}_{2} \mathrm{O}, \mathrm{NH}_{4} \mathrm{OH}, \mathrm{NH}_{4} \mathrm{Cl}$, and thiourea. The concentrations were $0.0036 \mathrm{M}, 0.360 \mathrm{M}, 0.024 \mathrm{M}$, and $0.009 \mathrm{M}$, respectively. The deposition temperature was kept at $70^{\circ} \mathrm{C}$ using a water bath, and the deposition time was $45 \mathrm{~min}$ with continuous stirring. The achieved film thickness was about $100 \mathrm{~nm}$. After the CdS deposition, the Glass/Mo/CIGS/CdS portion of the cell was subjected to further annealing in a sulfur and argon atmosphere at $200^{\circ} \mathrm{C}$ for $30 \mathrm{~min}$ to increase the density of the CdS layer.

The $\mathrm{ZnO}$ film was then deposited using the Denton sputtering tool. Some experimentation with this layer was necessary in order to achieve a high transparency and low resistivity. The optimal parameters to form a $100 \mathrm{~nm} \mathrm{ZnO}$ thin film were (1) the current at $80 \mathrm{~mA}$, (2) an $\mathrm{Ar} / \mathrm{O}_{2}$ flow of $21 \mathrm{sccm} / 14 \mathrm{sccm}$, (3) the chamber pressure of $0.67 \mathrm{~Pa}$, and (4) a temperature of $160^{\circ} \mathrm{C}$. The resulting $\mathrm{ZnO}$ film exhibited resistivity of $3.1 \times 10^{3} \mathrm{ohm}-\mathrm{cm}$ with $90 \%$ transparency. The $\mathrm{ZnO}: \mathrm{Al}$ film was deposited with the same sputtering tool. However, for this layer, RF sputtering was used. The composition of the RF target was $\mathrm{ZnO}$ with $2 \mathrm{wt} \% \mathrm{Al}_{2} \mathrm{O}_{3}$. The $\mathrm{RF}$ power was kept at $100 \mathrm{~W}$ and the substrate temperature was $160^{\circ} \mathrm{C}$. The achieved resistivity of the RF sputtered $\mathrm{ZnO}: \mathrm{Al}$ was $9.0 \times 10^{-3} \mathrm{ohm}-\mathrm{cm}$ with $90 \%$ transparency at $700 \mathrm{~nm}$ wavelength. The thickness of the $\mathrm{ZnO}$ :Al used in the solar cell was around $400 \mathrm{~nm}$.

The device was completed by applying Ag paste in a line for the top contact. The electrical contacts were then made to the silver paste on the top and the Mo layer on the bottom.

2.2. Synthesis of CuIn ${ }_{0.75} \mathrm{Ga}_{0.25} \mathrm{~S}_{2}$ Wurtzite Nanoparticles. Equal amounts of SSPs 1 and $2,\left(\mathrm{Ph}_{3} \mathrm{P}\right)_{2} \mathrm{Cu}(\mu \text {-SEt })_{2} \mathrm{In}(\mathrm{SEt})_{2}$ (SSP 1, $6.00 \mathrm{~g}, 6.33 \mathrm{mmol})$ and $\left(\mathrm{Ph}_{3} \mathrm{P}\right)_{2} \mathrm{Cu}(\mu \text {-SEt })_{2} \mathrm{Ga}(\mathrm{SEt})_{2}$ (SSP 2, 5.71 g, $6.33 \mathrm{mmol}$ ), are dissolved in dried benzene $(60 \mathrm{~mL})$ in the presence of one equiv of 1,2-ethanedithiol $(1.06 \mathrm{~mL}, 12.66 \mathrm{mmol})$. The mixture was stirred at room temperature for $5 \mathrm{~min}$ and the liquid was evaporated off to afford a solid precursor 3. In a dry Milestone microwave vessel, the precursor $3(1.714 \mathrm{~g})$ and $\left(\mathrm{Ph}_{3} \mathrm{P}\right)_{2} \mathrm{Cu}(\mu-\mathrm{SEt})_{2} \mathrm{In}(\mathrm{SEt})_{2}$ (SSP 1, $1.243 \mathrm{~g}$ ) was dissolved in benzyl acetate $(20.0 \mathrm{~mL})$ followed by addition of 3-mercaptopropionic acid $(4.0 \mathrm{~mL})$. The solution was capped and stirred for $5 \mathrm{~min}$ at room temperature. The reaction mixture was then irradiated with microwaves in a Milestone Microwave (Labstation ETHOS EX). The reaction was ramped for $15 \mathrm{~min}$ to reach the temperature of $240^{\circ} \mathrm{C}$ and was held for $1 \mathrm{~h}$. Upon completion, the reaction was cooled to room temperature to yield black precipitation of $\mathrm{CuIn}_{0.75} \mathrm{Ga}_{0.25} \mathrm{~S}_{2}$ Wurtzite nanoparticles. The resulting nanoparticles were isolated from the benzyl acetate solution by centrifugation and washed three times with $\mathrm{CH}_{3} \mathrm{OH}$ to remove any impurities. The product was then dried in vacuo to provide a black powder. The nanoparticles were dispersed in toluene as $20 \mathrm{wt} \%$ ink.

Characterization of the nanoparticles was performed with a JEOL 2010 high-resolution transmission electron microscope (HRTEM) with a spatial resolution of $0.194 \mathrm{~nm}$. Powder X-ray diffraction (XRD) patterns were acquired with a Bruker D8 Discover diffractometer using CuKa radiation and a scintillation detector. Scans were collected for $4 \mathrm{hrs}$ employing a $0.06^{\circ}$ step width at a rate of $10 \mathrm{~s} / \mathrm{step}$ resulting in a $2 \theta$ scan range from $10-60^{\circ}$.

\section{Results and Discussion}

As seen in Figure 2, the XRD data of CIGS thin film made from the Wurtzite phase nanoparticles displays three characteristic peaks between $2 \theta$ of 25 and 33 with significant broadness indicating small nanoparticle sizes. Upon annealing at $450^{\circ} \mathrm{C}$ for 1 hour, in a sulfur and argon atmosphere, the peaks converged and the characteristic XRD pattern for Chalcopyrite phase emerged. The widths of the peaks in the post-annealed XRD trace clearly show that the films made 


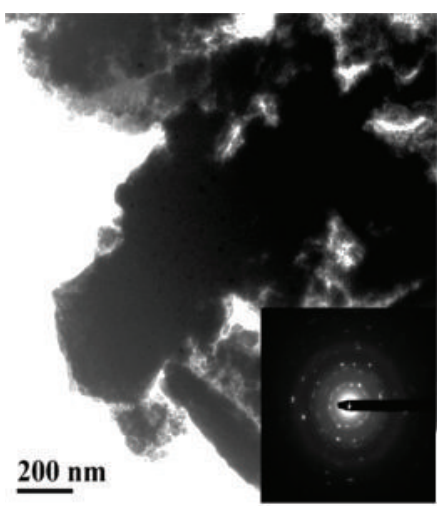

(a)

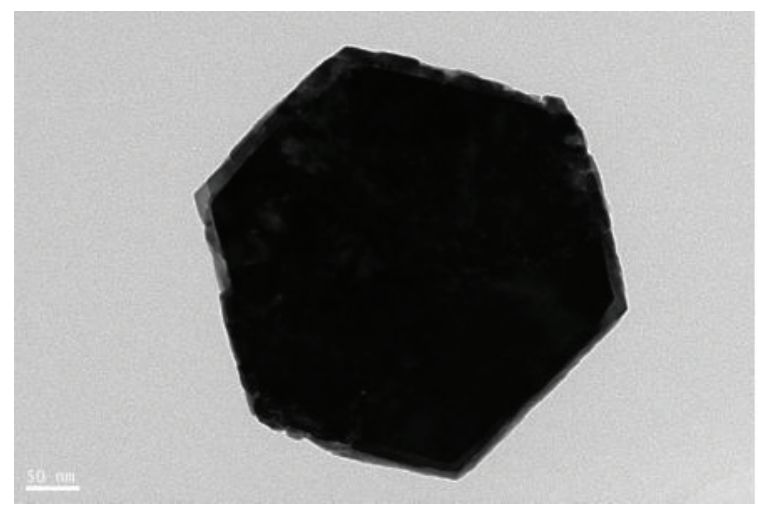

(b)

FIGURE 1: TEM micrograph with SAED inserts of the Wurtzite CIGS nanoparticles.

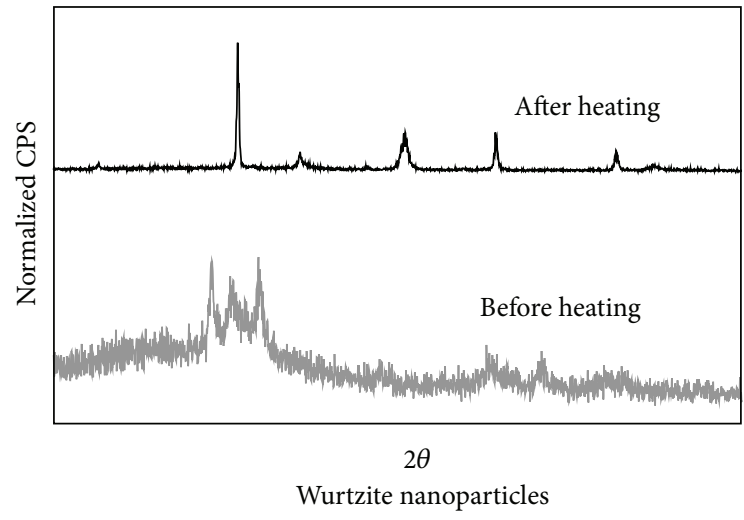

FIGURE 2: XRD spectra of the nanoparticles before and after annealing.

from Wurtzite CIGS nanoparticles were converted into a large crystalline Chalcopyrite phase film indicated by sharp peaks [6].

In Figure 3, SEM images of thin films deposited with the Wurtzite nanoparticles before and after annealing show that the grain sizes have grown to about $150 \mathrm{~nm}$ after annealing. Although a significantly larger grain size cannot be clearly seen in the SEM images, the nanoparticles appear to have fused together to make a continuous path for the carriers.

The light collecting area of the solar cells was measured to be about $0.25 \mathrm{~mm}^{2}$. A Sciencetech AM 1.5 Solar Simulator was used as the light source and electrical characteristics were measured using a Keithley 2400 source meter. Calibration of the light intensity was accomplished with an Ocean Optics light sensor. Cell parameters were derived from the currentvoltage $(I-V)$ curves, (Figure 4), of the solar cell. The efficiency of our best CIGS Wurtzite solar cell was reported in Table 1 in comparison to our best CIGS Chalcopyrite solar cell. An efficiency of $1.6 \%$ with a fill factor (ff) of 0.42 was achieved for the solar cell made from CIGS Wurtzite phase nanoparticles.
There are several potential explanations for why our Wurtzite-based solar cells had better efficiency than the cell constructed with Chalcopyrite nanoparticles. One explanation is that our hexagonal plate Wurtzite phase nanoparticles were much bigger in size thus had less surface area than smaller spherical Chalcopyrite phase nanoparticles. Less surface area means less organic passivation layer that needs to be removed to achieve a well-connected, large grain size CIGS layer. From our previous experience, the annealing temperature using Chalcopyrite phase nanoparticles normally needs to be $550^{\circ} \mathrm{C}$ or higher. We have observed that annealing Wurtzite nanoparticles at $450^{\circ} \mathrm{C}$ provide similar or better PV properties than Chalcopyrite nanoparticles that are annealed at $550^{\circ} \mathrm{C}$.

A second explanation is that Wurtzite-based solar cells should show higher efficiency than our own Chalcopyritebased solar cells is related to the relative stability of the Wurtzite phase. Since, the Wurtzite phase is a metastable phase, conversion to the Chalcopyrite phase results in a net release of energy, once the activation barrier has been overcome. The larger Wurtzite nanoparticles thus must lose energy to become large Chalcopyrite particles, and the excess energy could be used to shed the passivation layers allowing for a larger grain size.

Finally, when making solar cells using Wurtzite phase nanoparticles, the phase change of the nanoparticles from Wurtzite to Chalcopyrite is accompanied by a density change. For $\mathrm{CuIn}_{0.75} \mathrm{Ga}_{0.25} \mathrm{~S}_{2}$, the unit cell parameters are $a=$ $0.3890 \mathrm{~nm}, c=0.6411 \mathrm{~nm}$ for Wurtzite and $a=0.56675 \mathrm{~nm}$, $c=1.1275 \mathrm{~nm}$ for Chalcopyrite, and these values yield calculated densities of $4.57 \mathrm{~g} / \mathrm{cm}^{3}$ and $4.24 \mathrm{~g} / \mathrm{cm}^{3}$, respectively. The more dense Wurtzite material is converted to the less dense Chalcopyrite phase during the $450^{\circ} \mathrm{C}$ annealing step. The volume per mass must increase suggesting that the CIGS material must swell. This swelling would likely help reduce the presence of defect sites and produce a more efficient absorber layer in the final cell.

Figure 4 shows the current-voltage (IV) plots in the light and in the dark of a solar cell processed from CIGS Wurtzite phase nanoparticles. These $I V$ plots and the fill factor given in Table 1 are comparable with many published results using 


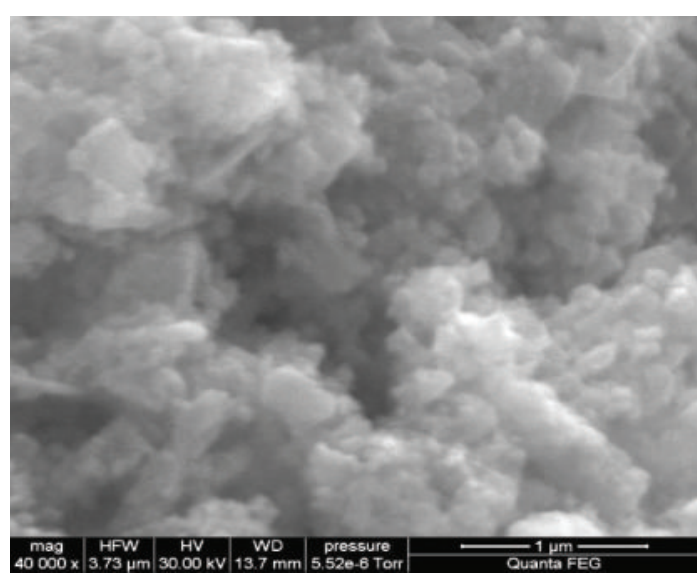

(a)

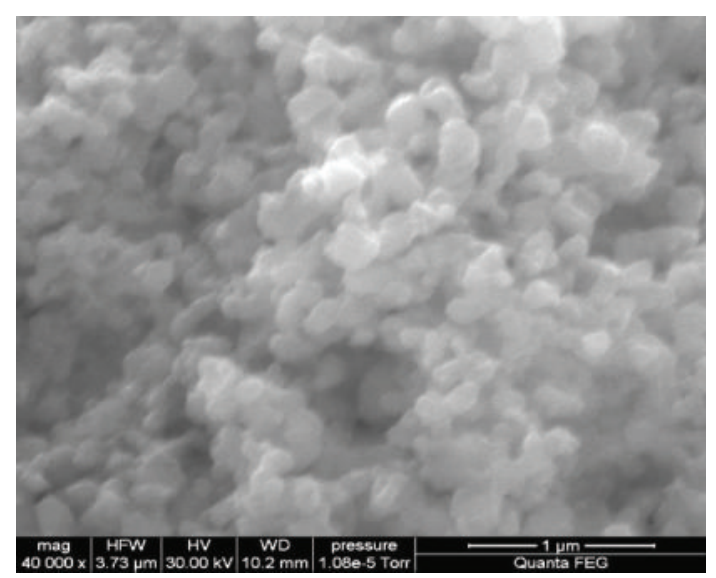

(b)

FIGURE 3: SEM images of the Wurtzite nanoparticles deposited in a thin film. The preannealed image is on the left, and the postannealed figure is on the right.

TABLE 1: Comparison of cell properties including open-circuit voltage, short-circuit current, between Wurtzite-based and Chalcopyrite-based solar cells annealed at $450^{\circ} \mathrm{C}$.

\begin{tabular}{lccccc}
\hline Initial phase & $V_{\mathrm{oc}}(\mathrm{mV})$ & $I_{\mathrm{sc}}\left(\mathrm{mA} / \mathrm{cm}^{2}\right)$ & Max Power $(\mu \mathrm{W})$ & Fill factor & $\%$ Efficiency \\
\hline Chalcopyrite (device 1) & 20 & 2 & 0.04 & 0.35 & 0.015 \\
Wurtzite (device 2) & 230 & 15 & 3.8 & 0.42 & 1.6 \\
\hline
\end{tabular}

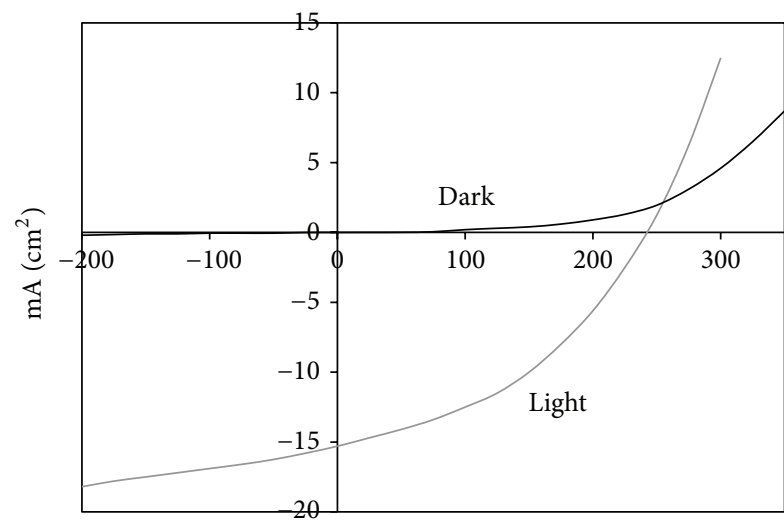

$(\mathrm{mV})$

FIGURE 4: Representative $I-V$ curves for a Wurtzite-based solar cell collected in the dark and in the light.

Chalcopyrite thin films, which were normally fabricated at $450^{\circ} \mathrm{C}$ or higher annealing temperatures [22]. In addition, for comparison, our own reference Chalcopyrite reference cells had much lower efficiency of $0.015 \%$ and a fill factor of 0.35 when constructed in analogous manner. Thus, the use of Wurtzite phase CIGS nanoparticles as a basis for the production of the absorber layer has no detrimental effects and has the potential to produce nanoparticle-based solar cells with higher efficiency than cells made from the Chalcopyrite phase nanoparticles.

\section{Conclusion}

In conclusion, an alternative route using CIGS Wurtzite nanoparticles for the fabrication of CIGS thin film photovoltaic devices has been demonstrated. The $0.25 \mathrm{~mm}^{2}$ solar cell showed an efficiency of $1.6 \%$ with a fill factor of 0.42 . The $I_{\mathrm{sc}}$ and $V_{\mathrm{oc}}$ of the cell were $15 \mathrm{~mA} / \mathrm{cm}^{2}$ and $230 \mathrm{mV}$, respectively after annealing the cell by a single step in a sulfur and argon atmosphere at $450^{\circ} \mathrm{C}$. The utility of CIGS Wurtzite nanoparticles is promising for a high-throughput and high-yield process for low-cost thin film solar cells. The large Wurtzite particle size, less organic ligands, and density change associated with converting the Wurtzite phase to Chalcopyrite phase may all play an important role on making a better quality absorber layer with less defects and less energy. These properties are critical for improving the thin film CIGS solar cell's performance. Further optimization of the annealing process by increasing the annealing temperature and adjusting the time or by using a RTA process will likely further improve the cell efficiency.

\section{Acknowledgments}

The authors Chivin Sun, Rene G. Rodriguez, and Joshua J. Pak would like to acknowledge partial support from DOE EPSCoR Grant no. (DE-FG02-04ER46142) for this work. Analysis of materials in this work was partially supported by the National Science Foundation under Grant no. (NSF CHE-1048714). Synthetic efforts in this work were partially supported by the National Science Foundation under Grant no. (NSF CHE-108952). The authors would also like to thank Anna Hoskins for help with the electrical measurements and 
Aaron Thurber at Boise State University for the assistance with TEM work.

\section{References}

[1] Q. Guo, G. M. Ford, H. W. Hillhouse, and R. Agrawal, "Sulfide nanocrystal inks for dense $\mathrm{Cu}\left(\mathrm{In}_{1-x} \mathrm{Ga}_{x}\right)\left(\mathrm{S}_{1-y} \mathrm{Se}_{y}\right)_{2}$ absorber films and their photovoltaic performance," Nano Letters, vol. 9, no. 8, pp. 3060-3065, 2009.

[2] Q. Guo, S. J. Kim, M. Kar et al., "Development of CulnSe nanocrystal and nanoring inks for low-cost solar cells," Nano Letters, vol. 8, no. 9, pp. 2982-2987, 2008.

[3] B. D. Weil, S. T. Connor, and Y. Cui, "CuInS 2 solar cells by airstable ink rolling," Journal of the American Chemical Society, vol. 132, no. 19, pp. 6642-6643, 2010.

[4] M. G. Panthani, V. Akhavan, B. Goodfellow et al., "Synthesis of $\mathrm{CuInS}_{2}, \mathrm{CuInSe}_{2}$, and $\mathrm{Cu}\left(\mathrm{In}_{x} \mathrm{Ga}_{1-x}\right) \mathrm{Se}_{2}$ (CIGS) nanocrystal "inks" for printable photovoltaics", Journal of the American Chemical Society, vol. 130, no. 49, pp. 16770-16777, 2008.

[5] L. Li, N. Coates, and D. Moses, "Solution-processed inorganic solar cell based on in situ synthesis and film deposition of $\mathrm{CuInS}_{2}$ nanocrystals," Journal of the American Chemical Society, vol. 132, no. 1, pp. 22-23, 2010.

[6] Q. Yunxia, L. Qiangchun, T. Kaibin, L. Zhenghua, R. Zhibiao, and L. Xianming, "Synthesis and characterization of nanostructured wurtzite $\mathrm{CuInS}_{2}$ : a new cation disordered polymorph of $\mathrm{CuInS}_{2}$," Journal of Physical Chemistry C, vol. 113, no. 10, pp. 3939-3944, 2009.

[7] M. E. Norako and R. L. Brutchey, "Synthesis of metastable wurtzite CuInSe $\mathrm{C}_{2}$ nanocrystals," Chemistry of Materials, vol. 22, no. 5, pp. 1613-1615, 2010.

[8] M. E. Norako, M. A. Franzman, and R. L. Brutchey, "Growth kinetics of monodisperse $\mathrm{Cu}$-In-S nanocrystals using a dialkyl disulfide sulfur source," Chemistry of Materials, vol. 21, no. 18, pp. 4299-4304, 2009.

[9] D. Pan, L. An, Z. Sun et al., "Synthesis of Cu-In-S ternary nanocrystals with tunable structure and composition," Journal of the American Chemical Society, vol. 130, no. 17, pp. 5620-5621, 2008.

[10] S. K. Batabyal, L. Tian, N. Venkatram, W. Ji, and J. J. Vittal, "Phase-selective synthesis of $\mathrm{CuInS}_{2}$ nanocrystals," Journal of Physical Chemistry C, vol. 113, no. 33, pp. 15037-15042, 2009.

[11] Y.-H. A. Wang, X. Zhang, N. Bao, B. Lin, and A. Gupta, "Synthesis of shape-controlled monodisperse wurtzite $\mathrm{CuIn}_{x} \mathrm{Ga}_{1-x} \mathrm{~S}_{2}$ semiconductor nanocrystals with tunable band gap," Journal of the American Chemical Society, vol. 133, no. 29, pp. 11072-11075, 2011.

[12] S. T. Connor, C.-M. Hsu, B. D. Weil, S. Aloni, and Y. Cui, "Phase transformation of biphasic $\mathrm{Cu}_{2} \mathrm{~S}-\mathrm{CuInS}_{2}$ to monophasic $\mathrm{CuInS}_{2}$ nanorods," Journal of the American Chemical Society, vol. 131, no. 13, pp. 4962-4966, 2009.

[13] B. Koo, R. N. Patel, and B. A. Korgel, "Wurtzite-Chalcopyrite polytypism in $\mathrm{CuInS}_{2}$ nanodisks," Chemistry of Materials, vol. 21, no. 9, pp. 1962-1966, 2009.

[14] K. Nose, Y. Soma, T. Omata, and S. Otsuka-Yao-Matsuo, "Synthesis of ternary $\mathrm{CuInS}_{2}$ nanocrystals; phase determination by complex ligand species," Chemistry of Materials, vol. 21, no. 13, pp. 2607-2613, 2009.

[15] C. Steinhagen, V. A. Akhavan, B. W. Goodfellow et al., "Solution-liquid-solid synthesis of $\mathrm{CuInSe}_{2}$ nanowires and their implementation in photovoltaic devices," ACS Applied Materials and Interfaces, vol. 3, no. 5, pp. 1781-1785, 2011.
[16] U. Rau and H. W. Schock, Clean Electricity from Photovolatics, vol. 1, Imperial College Press, London, UK, 2001.

[17] C. Sun, J. S. Gardner, G. Long et al., "Controlled stoichiometry for quaternary $\mathrm{CuIn}_{\mathrm{x}} \mathrm{Ga}_{1-\mathrm{x}} \mathrm{S}_{2}$ chalcopyrite nanoparticles from single-source precursors via microwave irradiation," Chemistry of Materials, vol. 22, no. 9, pp. 2699-2701, 2010.

[18] C. Sun, R. D. Westover, G. Long et al., "A large-scale synthesis and characterization of quaternary $\mathrm{CuIn}_{\mathrm{x}} \mathrm{Ga}_{1-\mathrm{x}} \mathrm{S}_{2}$ chalcopyrite nanoparticles via microwave batch reactions," International Journal of Chemical Engineering, vol. 2011, Article ID 545234, 8 pages, 2011.

[19] K. R. Margulieux, C. Sun, L. N. Zakharov, A. W. Holland, and J. J. Pak, "Stepwise introduction of thiolates in copper-indium binuclear complexes," Inorganic Chemistry, vol. 49, no. 9, pp. 3959-3961, 2010.

[20] W. Hirpo, S. Dhingra, A. C. Sutorik, and M. G. Kanatzidis, "Synthesis of mixed copper-indium chalcogenolates. singlesource precursors for the photovoltaic materials $\mathrm{CuInQ}_{2}(\mathrm{Q}=$ S, Se)," Journal of the American Chemical Society, vol. 115, no. 4, pp. 1597-1599, 1993.

[21] K. K. Banger, M. H.-C. Jin, J. D. Harris, P. E. Fanwick, and A. F. Hepp, "A new facile route for the preparation of singlesource precursors for bulk, thin-film, and nanocrystallite I-IIIVI semiconductors," Inorganic Chemistry, vol. 42, no. 24, pp. 7713-7715, 2003.

[22] R. Brini, M. Kanzari, B. Rezig, and J. Werckmann, "Effect of annealing on properties of $\mathrm{CuInS}_{2}$ thin films," The European Physical Journal Applied Physics, vol. 30, no. 3, pp. 153-158, 2005. 

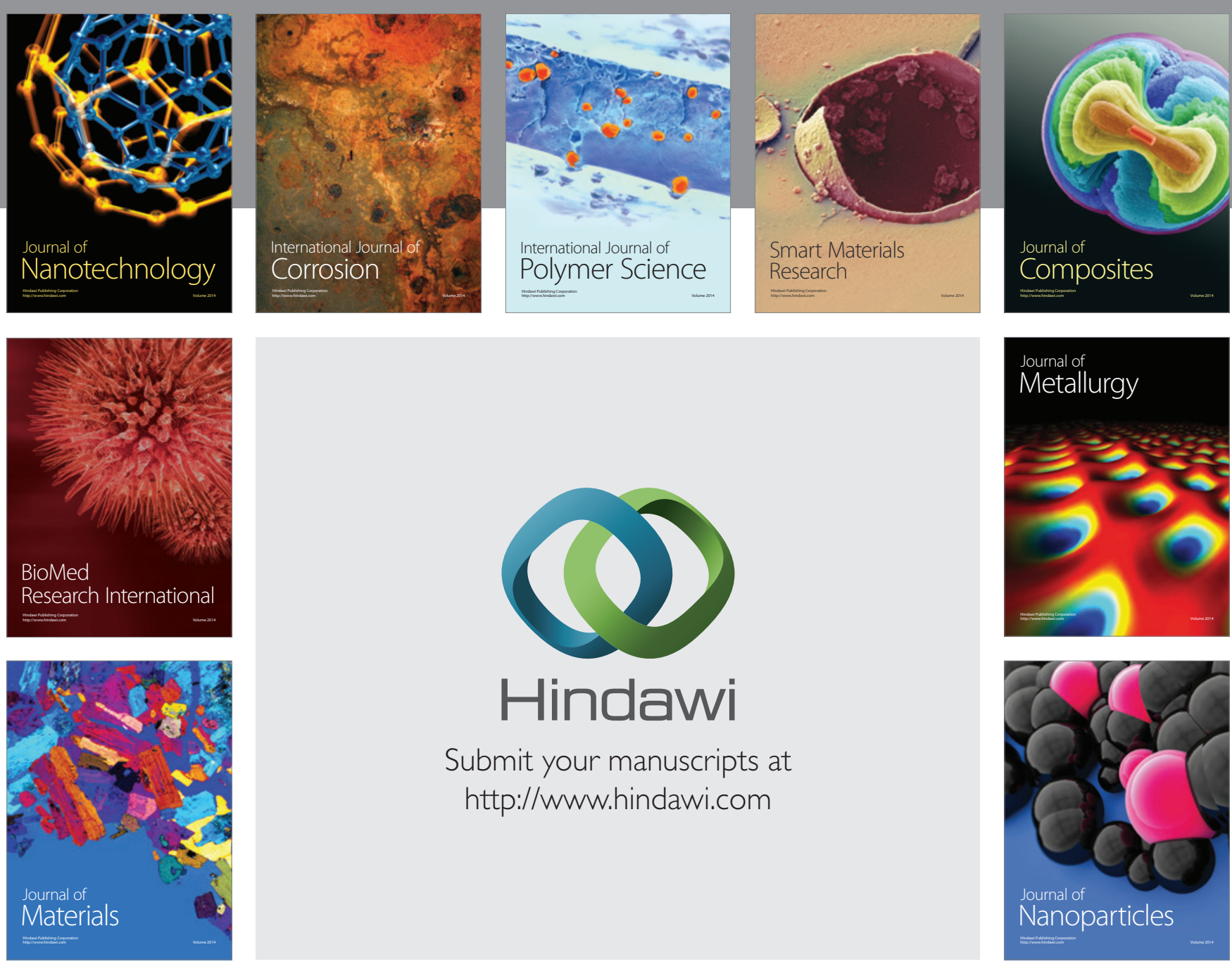

Submit your manuscripts at http://www.hindawi.com
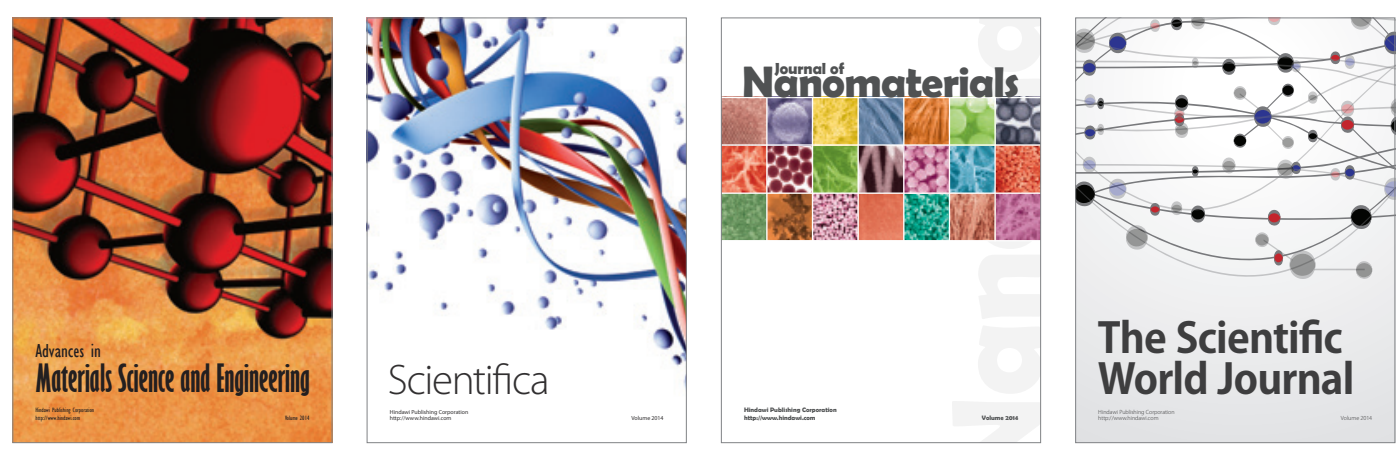

\section{The Scientific World Journal}
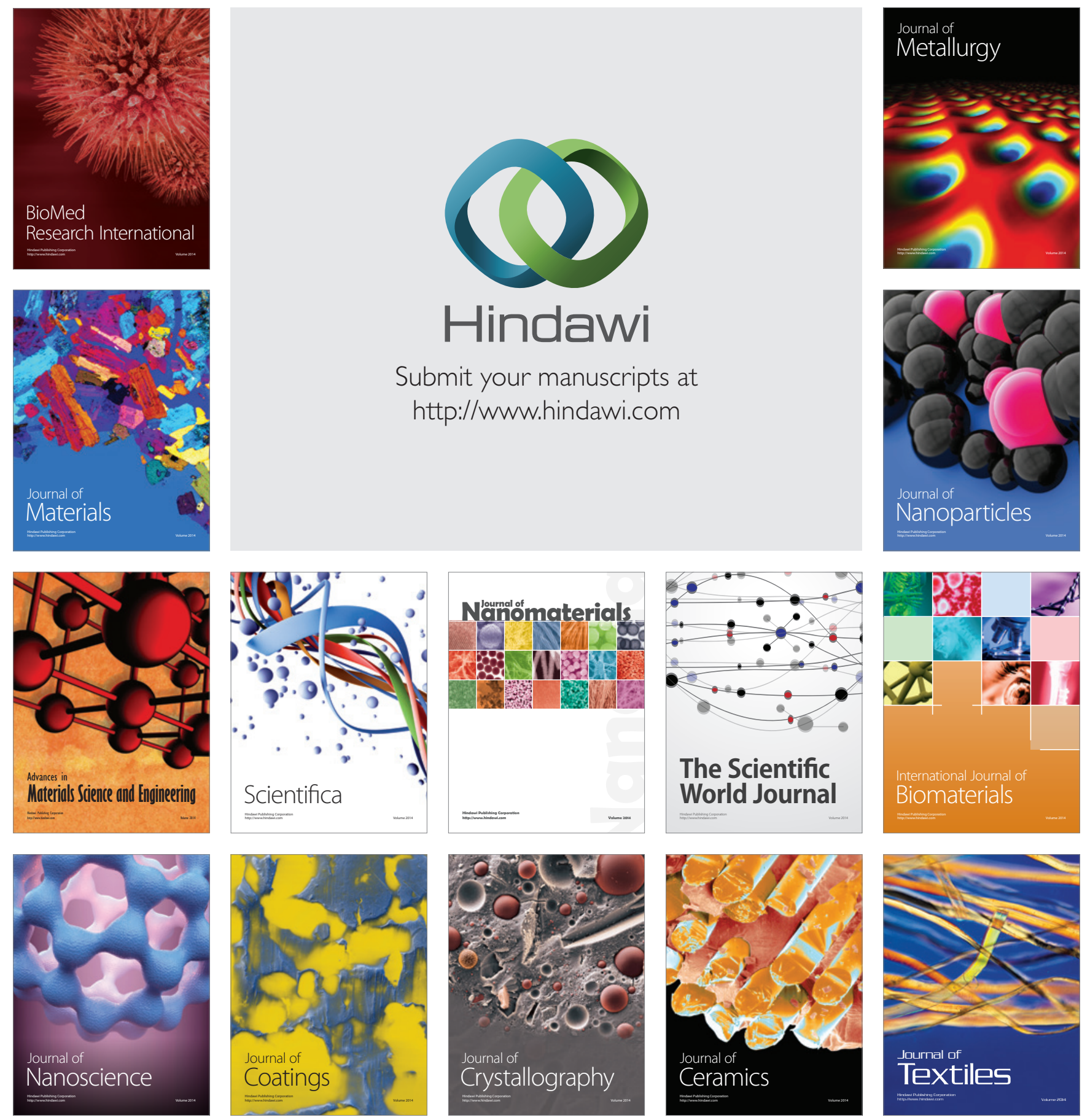